\title{
STATE AND LOCAL PENSION PLANS
}

\author{
Olivia S. Mitchell
}

Roderick Carr

Working Paper 5271

\section{NATIONAL BUREAU OF ECONOMIC RESEARCH 1050 Massachusetts Avenue \\ Cambridge, MA 02138 \\ September 1995}

The authors acknowledge research assistance from Trish Quarmby, and research support from The Wharton School and the Pension Research Council. Conclusions and opinions are those of the authors and do not reflect official policy of any of the institutions with which they are affiliated. This paper is part of NBER's research programs in Aging and Labor Studies.

(C) 1995 by Olivia S. Mitchell and Roderick Carr. All rights reserved. Short sections of text, not to exceed two paragraphs, may be quoted without explicit permission provided that full credit, including $\odot$ notice, is given to the source. 


\title{
STATE AND LOCAL PENSION PLANS
}

\begin{abstract}
This paper examines the role and function of pension plans covering state and local government employees in the United States. Covering about 16 million employees (including teachers, fire fighters, police, members of the judiciary, and many other state and local employees), these plans manage a substantial stock of financial assets -- close to $\$ 1$ trillion -- and receive annual contributions from employees and government revenues totaling about $\$ 56$ billion. Using data gathered from a variety of different sources, some of which have only recently become available, we describe the benefits, financing, and management of these plans, and identify some of the prominent challenges facing these pension plans in the next decade.
\end{abstract}

Olivia S. Mitchell

307 CPC - 3641 Locust Walk

The Wharton School

University of Pennsylvania

Philadelphia, PA 19104-6218 and NBER
Roderick Carr

The Wharton School

University of Pennsylvania

Philadelphia, PA 19104-6218 


\section{State and Local Pension Plans}

This paper describes the role and function of pension plans covering state and local government employees in the United States. These plans cover a wide range of occupations including teachers, fire fighters, police, members of the judiciary, and many other state and local employees. These plans have become the target of much public discussion of late, in part because so many people depend on them for retirement -- approximately 16 million participants, including $93 \%$ of the 12 million full-time state and local $(\mathrm{S} / \mathrm{L})$ workers, $53 \%$ of the 1.4 million part-time $\mathrm{S} / \mathrm{L}$ workers, and another 4 million plan beneficiaries. ${ }^{1}$ In addition $\mathrm{S} / \mathrm{L}$ plans as a whole manage a substantial stock of financial assets -- close to $\$ 1$ trillion -- and receive annual contributions from employees and government revenues totaling about $\$ 56$ billion. ${ }^{2}$ In terms of total assets, pension plans are on a par with private sector defined benefit plans.

Despite the extensive coverage and large size of these plans, until recently there has been little of a systematic nature written on them because of the dearth of high quality data. Private pension plans are required to provide relatively standardized information to the Labor Department under the Employee Retirement Income Security Act (ERISA). In contrast, state and local pension plans are not bound to disclose in a common format information regarding benefits, financing, and asset management patterns. For this reason, the present effort to identify key features of state and local pensions must necessarily rely on data gathered from a 
variety of different sources, some of which have only recently become available. In addition we identify some of the prominent challenges facing these pension plans in the next decade.

\section{Benefit Provisions of Public Sector Pension Plans}

The first public sector pension in the United States was the municipal plan established for New York City's police force in 1857; Massachusetts created the first state-wide plan in $1911 .^{3}$ Currently there are an estimated 2,500 plans in existence covering a wide range of local, municipal, and state-level employees. Most pensions covering state and local employees are defined benefit plans, and 9 out of 10 full-time $\mathrm{S} / \mathrm{L}$ employees are covered by this type of pension in which participation depends primarily on years of service, and eligibility for benefits is usually dependent on a combination of age and service. ${ }^{4}$ Public sector workers are more likely than their private sector counterparts to have retirement benefit coverage, inasmuch as pension coverage is about 15 percentage points higher in the public sector than for full-time employees of medium and large firms (BLS 1994a), ${ }^{5}$ and fifty percentage points higher than for full-time workers in small firms (BLS 1994b).

Comparisons of public and private pension plan characteristics along several key dimensions are facilitated with the help of Table 1. Here we see that public sector employees are generally included as participants in their plan immediately at hire, while private sector employees in medium and large firms must typically 
wait until they meet an age and/or service requirement. ${ }^{6}$ On the other hand, public sector workers take longer to vest: they generally work 10 years before becoming legally entitled to a benefit, whereas their private sector counterparts typically vest after five years (or at seven years if the employer uses a graded vesting rule).

Focusing next on benefit formulas, Table 1 indicates that public sector workers are less likely to be entitled to retire "early" but are more likely to be able to take "normal" benefits at a fairly young age -- particularly after attaining 30 years of service. Defined benefit plans as a rule provide higher retirement benefits to those with higher earnings and more years of employment, but benefit formulas differ markedly by sector. ${ }^{7}$ Public employee benefit formulas tend to depend on more heavily on earnings than do private plans, whereas the latter are more likely to offer a flat dollar benefit. A partial explanation for the relative importance of flat dollar benefits in private plans is their significance in blue collar union-negotiated plans, more common in the private sector than in the public sector. In both the public and private sector, pay-related benefits are more commonly associated with white collar jobs which are more common in the public sector. Public plans are substantially more likely to use the last three years of pay to determine the benefit amount, and private plans often use the final five years or some longer period such as one's career average pay. Retirement benefit formulas also differ according to the percentage of pay recognized per year of service. Among public employee plans, $44 \%$ of employees are covered by a formula which uses a multiplier of over $2 \%$ per 
year worked, while only $12 \%$ of private employees in medium/large firms have a benefit percentage this generous.

One reason public plans offer benefits which represent a higher percentage of pre-retirement pay is that about one quarter of public sector workers are not covered by social security (BLS 1994c). Even for those who participate in the social security system for a portion of their career, benefits accumulated are sometimes small. Differential social security coverage may also explain why post-retirement pension benefit increases are prevalent for state and local workers, with half covered by plans having an automatic adjustment; however, it should be noted that only about one-quarter receive full indexation to the consumer price index. ${ }^{8}$ Full indexation is extremely rare in private sector plans although pension augmentation at the discretion of the trustees of the plan provides partial preservation of the real value of benefits. Augmentation depends on the funding status of the plan and the generosity of the plan sponsor. For the members of the quarter of the public plans guaranteeing full indexation to the consumer price index, indexation represents a valuable and costly additional benefit. ${ }^{9}$

A different way to compare plan generosity across sectors is to examine pension benefit levels for hypothetical employees at the same pay level. Table 2 summarizes retirement benefits as a fraction of final earnings (replacement rates) for employees at three different pay rates and for various length-of-service records. The results show that lower-tenured public sector retirees receive benefits about fifty percent higher than their private sector counterparts, and higher-seniority 
workers receive a replacement rate at the same pay and service levels half to twothirds greater.

Besides regular retirement benefits, sometimes a participant may suffer a disabling event entitling him to a special disability pension. State and local pension plans tend to be relatively generous in their requirements for eligibility, probably because some of those covered by the plans are in jobs which expose them to substantial risk (for example, police and fire fighters). For instance, almost all (94\%) of full-time state and local employees have plans offering a disability benefit, as compared to $69 \%$ in the private sector comparison group. If disability strikes, $95 \%$ of $\mathrm{S} / \mathrm{L}$ employees can begin receiving benefits immediately, and few (3\%) would need to qualify for long term disability insurance. In contrast in the private sector, only $41 \%$ of those disabled could receive immediate benefits and a larger fraction (16\%) would have to qualify for long term disability insurance (BLS 1993, 1994a,c). It should be noted that the cost burden of long-term disability is typically placed on the pension plan in the public sector, whereas this cost in the private sector is usually separately covered by long-term disability programs (either through selfinsurance or insured plans). Hence public sector long term disability coverage is not necessarily better than private sector coverage, but long term disability in the public sector may be more likely to trigger early retirement and hence early pension entitlements. 


\section{Financing Public Pensions}

It is expensive to offer extensive pension participation together with generous and readily available retirement benefits, and the evidence suggests that at least in the aggregate, public sector plans are costly to maintain, more costly than private pensions. In 1992, for example, public employers paid $380 \%$ more per year per employee for retirement plan costs than did private employers. ${ }^{10}$ This gap in retirement plan costs is partly due to different earnings patterns across the two sectors, but even within broad occupations the differential persists. For instance, the S/L benefit advantage of white collar/professional employees has been computed at approximately $60 \%$, for blue collar workers $240 \%$, and for service workers 10 times. ${ }^{11}$ It must be noted that public sector employees help pay for their benefits more often than do their private sector counterparts: almost three-quarters of fulltime S/L participants are required to contribute an average of $6 \%$ or more of their pay, versus approximately $5 \%$ of private sector workers who contribute to their defined benefit plan (BLS 1994a). A full comparison of public/private sector contribution differences should take account of the fact that most private sector employees contribute to social security and often their pensions as well. Since some public sector employees are not covered by social security (or have only recently become integrated into that system), they rely more heavily on their $\mathrm{S} / \mathrm{L}$ plan which is often more generous, hence more costly, and more likely to require an employee contribution. 
To more closely examine state and local retirement plan financing, we turn next to a recent survey of state and local government defined benefit pension plans (Zorn 1994). This data file, collected for 1993 plan year data, includes a total of 449 plans covering 12.8 million participants or roughly three-quarters of the total universe of state and local pension plan members. An examination of the Table 3 highlights the extent of heterogeneity in this field. For example, average public pension plan size exceeds 28,000 participants, but the median pension plan has fewer than 1,300 participants. Nevertheless the breakdown by participant status is fairly similar irrespective of whether one takes a median or mean approach: roughly two-thirds to three-quarters of the participants are active members at present, with retirees making up the bulk of the remainder. ${ }^{12}$

A summary of the financial status of $\mathrm{S} / \mathrm{L}$ pension plans appears in Table 4, for both the average and the median public pension plan reporting financial data. ${ }^{13}$ Overall, the data highlight the fact alluded to earlier, namely that plan "averages" need not represent the median public pension plan. For example, assets per plan average $\$ 2.1$ billion, but the median plan holds $\$ 130$ million in assets. Liabilities (measured according to the projected benefit obligation method) average about $\$ 2.3$ billion, but are $\$ 167$ million in the median plan. Since both assets and liabilities move in tandem, the average of the stock funding rate (plan assets divided by liabilities) is quite close to the median plan's stock funding rate: 95 and $97 \%$. A slightly different way to gauge the magnitude of plan assets and liabilities appears in the second panel of Table 4, where per-participant figures are given. On 
average, per participant plan assets are about $\$ 95,000$ and liabilities about $\$ 107,000$ for an average stock funding rate of $89 \%$; by contrast, the median pension plan accumulation is about $\$ 62,000$ and liabilities total $\$ 66,600$, for a median stock funding ratio of $93 \%$. This difference between the median and mean per participant stock funding ratio is explained by recognizing that a few large plans are quite underfunded, dragging down the average.

Flow funding refers to the relationship between actual contributions in a given year, and those required based on actuarial projections. For the plans under study, average annual employer contributions total about $\$ 7,400$, versus a median of $\$ 5,600$ per member per year; both figures are smaller than required contributions. This is reflected by flow funding rates which average about $95 \%$; with smaller plans reporting higher rates, the median plan is fully funded on a flow basis. Focusing on contributions to the plans, employers contributed around $10 \%$ of covered payroll in 1992, matched with employee contributions of $6 \%$ of payroll. Employers contribute more in smaller plans - 15\% - as do employees - 7\% - making an average combined contribution rate of $22 \%$ of covered pay for smaller plans. Over fifty percent of plans have combined contribution rates in excess of $18.5 \%$ with roughly two dollars of employer contribution for each dollar of employee contributions. 


\section{Public Pension Plan Investment Performance}

Private pension law in the United States requires that pension trustees manage the assets for plan participants, and requires that pension investments be managed "prudently" -- in participants' best interests. The fact that U.S. public sector employee plans are not governed by ERISA has elicited questions about who should manage $\mathrm{S} / \mathrm{L}$ pension plan investments, and in which assets the funds should be held.

Available evidence on public pension plans indicates that most are directed by a board of trustees whose size varies across locales; judging from the evidence, there is clearly no unanimity about the optimal size or composition of these pension boards. For example, the mean (median) number of trustees per plan is 8 (7), but the smallest board has 3 while the largest in the sample has 28 members. Board composition also ranges widely, with political appointees holding an average of 4 seats on the board (median of 3), and active or retired employees 2-3 slots. Others often included on boards are ex-officio members, such as state treasurers. Between them, appointed and ex officio members of the board numerically dominate the public pension systems in a majority of cases.

What do these public pension system boards invest in? This question is becoming increasingly interesting as politicians begin to discuss investment targeting, sometimes referred to as "economically targeted investment". For private sector pension plans, U.S. Department of Labor has stated that nonfinancial criteria may be used to select among investments, if risk and return are identical. 
For public pension plans, no national guidelines exist and there is evidence that directing investments toward in-state projects may be associated with lower rates of return. ${ }^{14}$

Turning to the evidence, the upper panel of Table 5 indicates how S/L pension plans have allocated their portfolios in some detail, and the lower panel summarizes changes over time. Clearly asset allocation decisions have changed from several decades ago: current about $40 \%$ of public plan assets are held in stock, up from $3 \%$ in 1960 and $17 \%$ in 1970.

How well do public pension plan investments perform? In the Zorn (1994) data, median pension fund earnings over the period 1988-1992 came to $11.1 \%$ per year (compounded) and the average system reported 10.8\%. However performance varies widely: the poorest performing system reported a yield of $6.5 \%$ annually, less than half of the $14.2 \%$ annual rate achieved by the best performing system. It must be recognized that returns are not strictly comparable across plans without correcting for different portfolio mixes and accounting/reporting standards, a correction which is not feasible given available data. In addition, many plans do not report their investment performance results at all, so that examining only those who do might produce reporting bias. Of course, the difficulty of obtaining standard financial performance data for state and local plans makes it clear that plan participants and others cannot readily examine and hold managers accountable for fund performance. Furthermore, one in 10 public plans does not currently make summary plan descriptions and annual benefits statements 
available to employees on request; one in four plans sends an individual statement automatically each year.

Plan expenses are a related matter, insofar as they affect plan performance. There is some evidence that state and local pension systems are operating at relatively high levels of administrative costs, partly because there are so many small plans which cannot take advantage of all available scale economies. One study estimates that public pensions operate at $65 \%$ of potential efficiency, implying that substantial cost savings would probably be derived from consolidation and other improved management practices (Hsin and Mitchell 1995). While there is no evidence that larger plans have better investment returns per se, they do experience lower administrative costs per member: it has been estimated that the median public pension could save approximately $\$ 350,000$ per year $(\$ 1992)$ by consolidating with other pensions and thus operating more efficiently.

\section{Forces Driving Change}

Looking ahead, what forces will spell change in the public pension arena? One emerging problem is that of fiscal stress, or the difficulty states and localities have had gathering tax revenue needed to sustain $\mathrm{S} / \mathrm{L}$ government operations. This problem affects funding negatively, and also has led at least some plans to adopt less conservative actuarial assumptions in order to lessen their contributions (Mitchell and Smith 1994). Actuarial assumptions which appear to have the greatest impact in determining the assessment of the obligations of a pension plan 
to pay future benefits, and over which the actuaries and the trustees can exercise the greatest discretion, are the forecast investment return and inflation rate. This difference (yield rate minus inflation rate) is called the "spread" rate: in general, the narrower the spread, the greater the projected amount of contributions required to fund a given level of benefits. Over the next forty years, plan managers in the Zorn (1994) file assume that investment returns will be $5-10 \%$ per year, and inflation rates $5.5-7 \%$. The spread rate implied by these assumptions ranges from a low of $1 \%$ to a high of $5.2 \%$ per year, with the median (average) plan in the survey opting for $3 \%(2.8 \%)$. Unfortunately, without standardized actuarial assumptions, it is difficult to compare the absolute and relative strength of individual public pension plans, and deteriorating funding status might be disguised by unrealistic actuarial assumptions.

Looking down the road, it seems clear that $\mathrm{S} / \mathrm{L}$ pension plans will face increased pressure in the next decade and beyond due to aging of their participants and budget stringencies (Inman 1982). A shrinking federal government may devolve additional costs on state and local governments, which could increase the needed size of S/L labor forces. However this would put into sharper perspective the large sums already being spent to maintain public employee retirement plans. On another front, there is a possibility that state and local employees will follow the lead of their private sector counterparts and begin to demand self-directed pension accounts of the defined contribution variety. At present, only nine percent of S/L employees have a defined contribution plan (BLS 1994c), but it is to be expected 
that younger workers will find this alternative increasingly attractive over time. If such plans are second-tier accounts added to existing arrangements, they contain the potential for increased costs. Also if current young participants are permitted to opt out of the defined benefit public plans in favor of defined contribution arrangements, these defined benefit plans will increasingly face actuarial deficits as plan membership ages more rapidly than assumed when contribution rates were initially set.

It was noted above that about a quarter of public sector employees do not contribute to and are not therefore entitled to benefits from social security. One issue that emerges in this regard is the potential for future social security system reforms to integrate these workers into the national system, on grounds of equity and cost-savings. This of course could force dramatic changes in existing $\mathrm{S} / \mathrm{L}$ pension arrangements. In addition, about a third of state and local pension plan benefit formulas are currently integrated with social security benefits, meaning that proposed reforms in that national system could impose as yet unknown future liabilities on state and local plans. In general, efforts to reform the nation's insolvent social security system will no doubt have far-reaching effects on state and local pension plans.

Tax reform also holds the prospect of unleashing forces for significant change. For example the "flat tax" proposals would probably reduce the appeal of pensions as tax preferred savings vehicles, leading at least some workers to favor cash compensation over pensions. Certainly many private sector employers might 
shed the complexity and regulatory burden associated with pension plans if tax qualification rules were changed dramatically. Whether public employee pension plans would change dramatically is not clear, but certainly a flat tax regime would bring major changes to that environment as well.

\section{Conclusions}

Current participants in state and local government employee pensions appear to be relatively well off, on the basis of available information. These S/L plans appear to pay relatively generous benefits, with (often indexed) benefits replacing $35-50 \%$ of preretirement pay. Most of these plans are also reasonably well-funded as a rule. Public sector pension plan assets, now close to $\$ 1$ trillion, appear to be more diversified now than in the past, perhaps due to the influence of professional money managers who often participate in $\mathrm{S} / \mathrm{L}$ pension investment decisions.

Despite these and other signs of health in the state and local pension sector, these retirement benefit plans face numerous challenges over the next several decades. As the baby boom generation begins to retire, the plans will mature and contributions may begin to fall below benefit payouts. This is per se not a problem, but will exacerbate other internal and external pressures to which public pension boards have become subject in recent years.

One of the external pressures facing pension boards is political: several $\mathrm{S} / \mathrm{L}$ plans have adopted nonfinancial criteria in making their pension asset allocation 
decisions, a practice that seems appealing politically but one which sometimes yields higher financial risk. Another external pressure is fiscal stress which undermines efforts to fully fund accumulating promises, and often drives the choice of actuarial and other assumptions used in setting employer contribution rates. These external pressures become internalized when public pension boards become dominated by political appointees, as we have shown is often the case. And when retired and active participants serve on the boards, they are frequently not well informed. A more uniform set of reporting and disclosure requirements for public pension finances would help taxpayers and participants better understand how state and local pension systems work, and would strengthen these plans against fiscal and political pressures in the decades to come. 


\section{References}

Bleakney, Thomas P. Retirement Systems for Public Employees. Philadelphia PA: Pension Research Council, 1972.

Braden, Bradley R. and Stephanie Hyland. "Cost of employee Compensation in the Public and Private Sectors". In Employee Benefits Survey: A BLS Reader. USDOL, BLS, February 1995.

Bureau of Labor Statistics (BLS), US Department of Labor. Employee Benefits in Medium and Large Firms, 1989 and 1993. Washington, D.C.: US GPO, 1990 and 1994(a).

Bureau of Labor Statistics (BLS), US Department of Labor. Employee Benefits in Small Private Establishments, 1992. Washington, D.C.: US GPO, 1994(b). Bureau of Labor Statistics (BLS), US Department of Labor. Employee Benefits in State and Local Governments, 1990 and 1992. Washington, D.C.: US GPO, 1992 and 1994(c).

Durgin, H. "Politicians Grabbing Pension Assets." Pensions and Investments. July 8, 1991.

Gustman, Alan and Thomas Steinmeier. "Cost of Living Adjustments in Pensions". In The Aging Workforce. Edited by Olivia S. Mitchell. Ithaca, NY: ILR Press, 1993.

Hoffman, Arnold and John Mondejar. "Pension Assets and Financial Markets, 1950 - 1989". In Trends in Pensions 1992, John A. Turner and Daniel J. Beller, Eds. USGPO, 1992. 
Hsin, Ping-Lung and Olivia S. Mitchell. "Managing Public Sector Pensions". In Pensions for the Twenty-First Century, Eds. S. Scheiber and J. Shoven, Twentieth Century Fund. Forthcoming 1996.

Hsin, Ping Lung and Olivia S. Mitchell. "The Political Economy of Public Sector Pensions: Pension Funding Patterns, Governance Structures, and Fiscal Stress". Revista de Analysis Economico, July 1994.

Inman, Robert P. "Public Employee Pensions and the Local Labor Budget". Journal of Public Economics 19 (1982): 49-71.

Ippolito, Richard A. Pensions, Economics and Public Policy. Pension Research Council. New York: Dow Jones Irwin. 1986.

McGill, Dan. "Public Employee Pension Plans", In Handbook of Employee Benefits, Ed. Jerry Rosenbloom, Third Edition, Business One Irwin, 1992.

Mitchell, Olivia S. and Ping-Lung Hsin. "Public Pension Plan Governance and Performance". NBER Working Paper January 1994.

Mitchell, Olivia S. and Robert S. Smith. "Pension Funding in the Public Sector". Review of Economics and Statistics (1994).

Phillips, Kristen. "State and Local Government Pension Benefits". In Trends in Pensions 1992. Edited by John Turner and Lorna Dailey. Washington, D.C.: USGPO, 1992: 341-492.

Salisbury, Dallas and Nora S. Jones, Eds. Pension Funding and Taxation, Washington, D.C.: Employee Benefit Research Institute, 1994. 
Verhovek, S. H. "States are Finding Pension Funds Can Be a Bonanza Hard to Resist." New York Times, Apr. 22, 1990.

Zorn, Paul. Survey of State and Local Government Employee Retirement Systems. Government Finance Officers Association. November 1991.

Zorn, Paul. Survey of State and Local Government Employee Retirement Systems. Government Finance Officers Association. 1994. 
Table 1.

Public and Private Defined Benefit Pension Plan Design Features

(Percent of full-time pension plan participants)

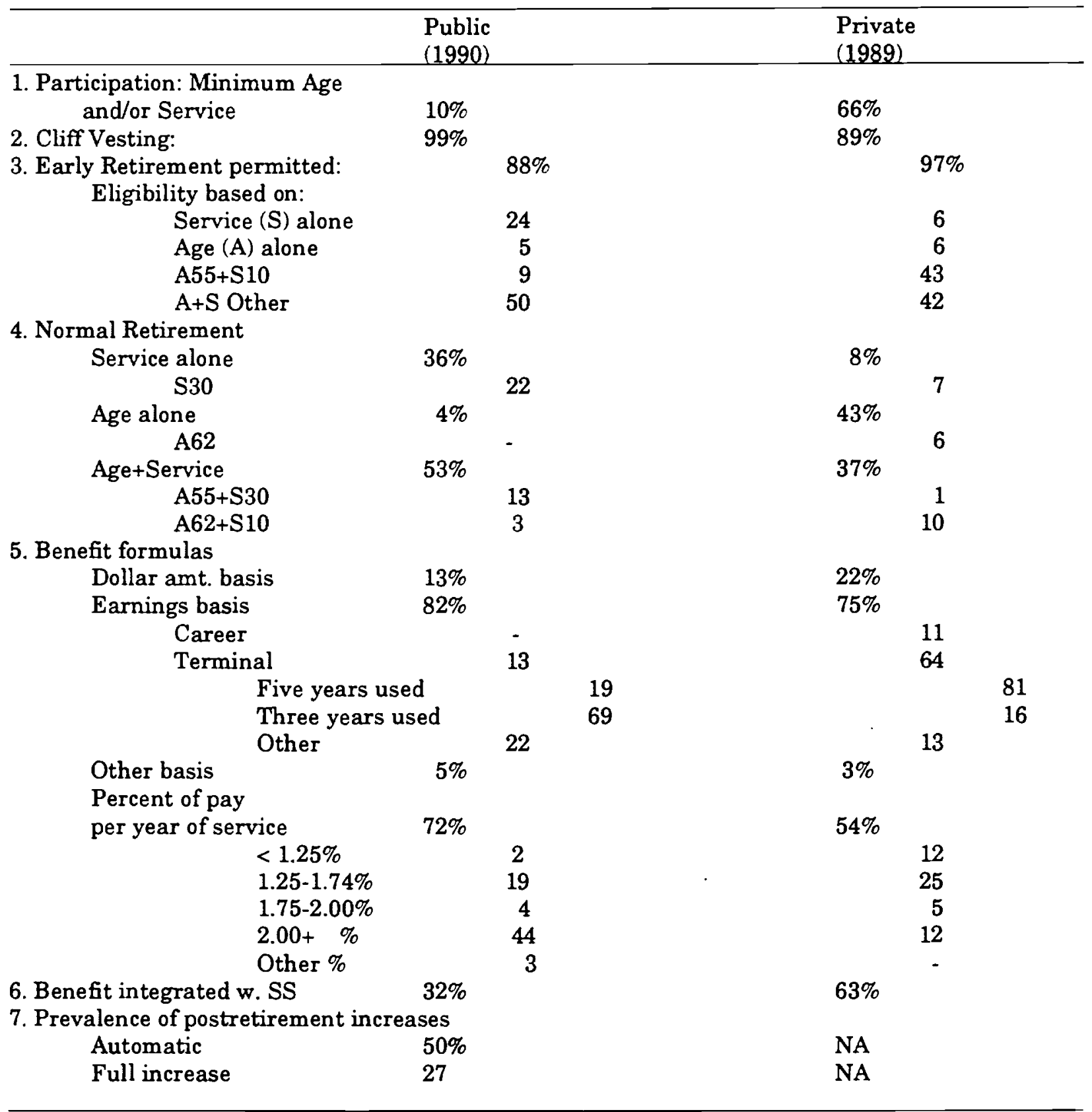

Source: Adapted from Hsin and Mitchell (forthcoming)

Notes: - Not reported by BLS because fraction less than 0.5 percent.

NA Not available from BLS

* Public refers to S/L employees; private refers to medium and large private (BLS 1994a\&c) 
Table 2.

Public and Private Defined Benefit Pension Replacement Rates*

(Percent of full-time pension plan participants)

\begin{tabular}{cll}
\hline & $\begin{array}{c}\text { Public } \\
(1990)\end{array}$ & $\begin{array}{c}\text { Private } \\
(1989)\end{array}$ \\
\hline Replacement Rate: Retirement benefit as a \% of final earnings & \\
At 20 years of service & & \\
Salary $\$ 15 \mathrm{~K}$ & $34 \%$ & $23 \%$ \\
Salary 25K & 34 & 20 \\
Salary 35K & 34 & 20 \\
& & \\
At 30 years of service & $52 \%$ & $35 \%$ \\
Salary $\$ 15 \mathrm{~K}$ & 52 & 30 \\
Salary 25K & 44 & 30 \\
Salary 35K & & \\
& &
\end{tabular}

Source: Hsin and Mitchell (forthcoming)

Notes:* Public refers to state and local employee; private refers to medium and large firms (BLS $1994 a \& c)$. 
Table 3.

State and Local Pension Plan Membership

\begin{tabular}{lcccc}
\hline & Average & Median & $\begin{array}{l}\text { Total } \\
\text { (million) }\end{array}$ & \# Plans \\
\hline Total participants (\#) & $\mathbf{2 8 , 4 0 0}$ & $1, \mathbf{2 6 9}$ & $\mathbf{1 2 . 8}$ & 449 \\
Active participants (\%) & $73 \%$ & $65 \%$ & 9.4 & 449 \\
Retired participants (\%) & $24 \%$ & $31 \%$ & 2.9 & 417 \\
Disabled participants (\%) & $2 \%$ & $2 \%$ & 0.2 & 417 \\
Other (\%) & $1 \%$ & $2 \%$ & 0.3 & 417
\end{tabular}

Source: Authors' calculations using Zorn (1994). 
Table 4.

Financial Status of State and Local Pension Plans*

\begin{tabular}{|c|c|c|c|}
\hline & Average & Median & All Sample Plans \\
\hline \multicolumn{4}{|l|}{ Per Plan (\$000) } \\
\hline Total Pension Plan Assets & $\$ 2,080,089$ & $\$ 129,834$ & $\$ 632,347,204$ \\
\hline Total Pension Benefit Obligation & $\$ 2,280,984$ & $\$ 167,308$ & $\$ 693,429,086$ \\
\hline Total Underfunding & $\$ 202,985$ & $\$ 936$ & $\$ 61,707,389$ \\
\hline \multicolumn{4}{|l|}{ Contributions $(\$ 000)$} \\
\hline Required Employer Contributions & $\$ 71,467$ & $\$ 4,383$ & $\$ 27,014,356$ \\
\hline Actual Contributions (Total) & $\$ 96,214$ & $\$ 5,688$ & $\$ 37,330,909$ \\
\hline Employer & $\$ 63,262$ & $\$ 3,775$ & $\$ 24,545,673$ \\
\hline Employee & $\$ 33,101$ & $\$ 1,103$ & $\$ 12,843,062$ \\
\hline Other & $\$ 1,720$ & $\$ 0$ & $\$ 667,295$ \\
\hline \multicolumn{4}{|l|}{ Stock Funding Ratio } \\
\hline Assets/PBO (\%) & $95 \%$ & $97 \%$ & $91 \%$ \\
\hline \multicolumn{4}{|l|}{ Flow Funding Ratio } \\
\hline Required/Actual Contributions & $95 \%$ & $100 \%$ & $91 \%$ \\
\hline \multicolumn{4}{|l|}{ Payments $(\$ 000)$} \\
\hline Total Benefit Payments & $\$ 80,564$ & $\$ 3,690$ & $\$ 30,292,216$ \\
\hline Retirement & $\$ 70,500$ & $\$ 3,094$ & $\$ 26,508,146$ \\
\hline Disability & $\$ 5,671$ & $\$ 178$ & $\$ 2,132,363$ \\
\hline Survivors & $\$ 3,504$ & $\$ 145$ & $\$ 1,317,578$ \\
\hline \multirow[t]{2}{*}{ Lump Sum } & $\$ 889$ & $\$ 0$ & $\$ 334,129$ \\
\hline & $\begin{array}{c}\text { \$ Weighted } \\
\text { Average }\end{array}$ & Median & $\begin{array}{l}\text { Plan Weighted } \\
\text { Average }\end{array}$ \\
\hline \multicolumn{4}{|l|}{ Per Participant $(\$)$} \\
\hline Plan Assets & $\$ 93,909$ & $\$ 62,136$ & $\$ 49,577$ \\
\hline Liabilities (PBO) & $\$ 107,238$ & $\$ 66,626$ & $\$ 54,365$ \\
\hline Contributions (\$) & $\$ 7,443$ & $\$ 5,568$ & $\$ 3,997$ \\
\hline
\end{tabular}

Source: Authors' calculations using Zorn (1994); year ending during 1992.

Note: * Subentries may not sum because they represent plan-weighted rather than dollarweighted means or medians. 
Table 5.

Investments of State and Local Pension Plans

\section{All Sample Plans}

\section{A. 1992 Summary}

Total

$100 \%$

Cash and Short Term $\quad 5 \%$

Bonds

US Govt

$49 \%$

Corporate

28

Mortgages

16

International

4

Equities

Domestic

39

International

Real Estate

3

Venture Capital

$3 \%$

$1 \%$

B. Changes Over Time (1950-1992)

\begin{tabular}{lccllll} 
& 1950 & 1960 & 1970 & 1980 & 1989 & 1992 \\
\hline Corporate Equities & $0 \%$ & $3 \%$ & $17 \%$ & $22 \%$ & $40 \%$ & $42 \%$ \\
Corporate Bonds & 12 & 36 & 58 & 48 & 27 & 21 \\
US Government Securities & 51 & 30 & 11 & 20 & 27 & 28 \\
Other & 37 & 31 & 14 & 10 & 6 & 9
\end{tabular}

Source: Panel A: Authors' calculations using Zorn (1994). Panel B: 1950 -1989: Hoffman and Mondejar (1992), T.16.9 and 10: 438-441; 1992: Authors' calculations using Zorn (1994) 


\title{
Endnotes
}

\begin{abstract}
'As will be noted throughout this chapter, data on U.S. state and local pension plans are difficult to obtain because there is no centralized clearing house for information on these plans. Figures on active participants are derived from BLS (1994c) and beneficiaries estimated using the ratio of beneficiaries to active participants from Zorn (1994).
\end{abstract}

${ }^{2}$ State and local pension fund assets and contributions are difficult to obtain, for U.S. plans. Assets are reported at $\$ 916$ billion in 1992 (Salisbury and Jones 1994); annual contributions are estimated by inflating annual contributions in Zom's (1994) subsample of pension plans by the ratio of total assets in Zorn (1994) to total assets in Salisbury and Jones (1994).

${ }^{3}$ Bleakney (1972) and McGill (1992) offer historical perspectives on public section pension plan development and legal framework.

${ }^{4}$ State and local government pension plan characteristics in the U.S. are summarized by Phillips (1992).

\footnotetext{
${ }^{5}$ Private sector part-time employees of medium and large firms have retirement plan coverage rates of $40 \%$, or 13 percentage points below the public employee rate (BLS 1994a).
}

\footnotetext{
${ }^{6}$ The figures given in Table 1 permit a comparison of pension plan characteristics for U.S. state/local workers with those in medium and large private establishments; plans covering workers
} 
in small firms are not included in the table. In the remainder of this section, comparisons with private sector plan participants will be limited to workers in medium and large firms (BLS 1994a).

' So few of these employees have a defined contribution plan (9\%), we will not address these further in the body of the discussion (BLS 1994c).

${ }^{8}$ In the private sector, it appears that post retirement benefit increases are rarely awarded on an automatic basis, and when ad hoc raises are granted, they equal about half the inflation rate (see Gustman and Steinmeier 1993).

${ }^{9}$ To the extent that public plans provide more frequent, more substantial post-retirement augmentation of pensions, even if only at the trustees' discretion, a public pension benefit is more likely to retain its real purchasing power than will a private pension benefit. For those retired public sector employees not covered by social security (the latter of which is indexed), indexation or generous post-retirement increases are vital if their standard of living in retirement is not to be eroded. Inflation at $5 \%$ per annum halves the purchasing power of money in 15 years.

${ }^{10}$ In 1992 , average hourly employer costs for retirement plans were $\$ 1.82$ per employee in the public sector versus $\$ 0.48$ for the private sector (Braden and Hyland 1993).

${ }^{11}$ Eamings differentials were somewhat smaller by occupation, though the gap was widest for service sector employees (Braden and Hyland 1993). 
${ }_{12}$ Private sector active defined benefit participants totaled 25.7 million in 1991 (US DOL 1995), versus 12 million actives in the state and local sector as a whole (BLS 1994c).

${ }^{13}$ The number of plans included in this analysis varies between 304 (for assets, PBO liabilities, and stock funding) and 342 (for required and actual contribution numbers needed for flow funding computations). The fact that all state and local pension plans do not readily supply these financial figures makes it difficult for retirees and taxpayers to obtain information regarding their public retirement systems.

${ }^{44}$ For media accounts see Durgin (1991) and Verhovek (1990); an academic investigation appears in Mitchell and Hsin (1994). 